\title{
CONSTRUÇÃO IDENTITÁRIA E FORMAÇÃO DE PROFESSORES "NATIVOS DIGITAIS" NO ESTÁGIO SUPERVISIONADO DE LÍNGUA INGLESA
}

\section{IDENTITY CONSTRUCTION AND “DIGITAL NATIVE” TEACHER EDUCATION IN THE ENGLISH LANGUAGE SUPERVISED INTERNSHIP}

\author{
Walter Vieira Barros*
}

\begin{abstract}
RESUMO
Este artigo analisa as influências de representações ou de mitos acerca do que é ser professor nas (auto)percepções de licenciandos "nativos digitais" frente às práticas envolvendo o smartphone por eles realizadas. Dessa forma, partimos da discussão acerca de como se entende as identidades na pós-modernidade, situando-a na área de formação docente. Para este artigo, apresentamos um recorte de uma pesquisa qualitativa de base etnográfica que foi desenvolvida no contexto de estágio supervisionado de língua inglesa, em que se buscou utilizar o smartphone. Foi possível observar como determinados mitos ou representações do que é ser professor podem causar angústia e culpa em alguns licenciandos devido a (im)posição de uma identidade docente que se tem como norma.
\end{abstract}

Palavras-chave: identidades; formação docente; estágio supervisionado.

\section{ABSTRACT}

This article analyses the influences of representations or myths about what it is to be a teacher in the (self)perceptions of "digital native" teacher trainees in the face of practices using the smartphone performed by them. Thus, it is discussed ways of understanding identities in post-modernity, placing it in the teacher education field. For this article, it is presented an excerpt from an ethnographic qualitative research that was developed in the context of an English teaching supervised internship, in which it was tried to use the smartphone. It was possible to observe how certain myths or representations of what it is to be a teacher may cause anguish and guilt in some teacher trainees due to the (im) position of a teacher identity considered to be the norm.

Keywords: identities; teacher education; supervised internship.

\section{CONSIDERAÇÕES INICIAIS}

Este trabalho é parte das discussões da pesquisa Letramentos digitais: um estudo com a mediação do smartphone no estágio supervisionado de língua inglesa no Ensino Médio (cf. BARROS, 2019) desenvolvida no Programa de Pós-Graduação em Linguagem e Ensino (PPGLE) da Universidade Federal de Campina Grande (UFCG). A referida pesquisa discute acerca das implicações do uso das Tecnologias Digitais de Informação e Comunicação (TDIC), mais especificamente do uso do smartphone, no ensino de língua inglesa e, consequentemente, para a formação do profissional no contexto de estágio supervisionado.

O estágio supervisionado em que a pesquisa foi realizada é o componente curricular Estágio de Língua Inglesa: $3{ }^{\circ}$ ano do Ensino Médio, ofertada no período de 09/04/2018 à 06/08/2018, no curso de Licenciatura em Letras - Língua Inglesa, pela Unidade Acadêmica de Letras, da Universidade Federal de Campina Grande. No referido componente curricular, havia dez licenciandos matriculados, que foram organizados em duplas ${ }^{2}$ para o desenvolvimento das atividades do estágio supervisionado, o qual foi dividido em três grandes etapas: a) a primeira etapa foi o momento em que ocorreram aulas com o professor-formador e com o estagiário docente ${ }^{3}$ na UFCG, para

\footnotetext{
* Mestre em Linguagem e Ensino pelo Programa de Pós-Graduação em Linguagem e Ensino (PPGLE) da Universidade Federal de Campina Grande (UFCG). Atualmente é professor de Língua Inglesa na Secretaria Municipal de Educação e Cultura de Esperança, Paraíba., Brasil. waltervieirabarros@gmail.com

Orcid: https://orcid.org/0000-0002-8802-2030

1. Pesquisa aprovada pelo comitê de ética, sob o número de CAAE: 85575518.5.0000.5182

2. Na dissertação (BARROS, 2019), os dez licenciandos foram denominados de L1, L2, L3 etc. de acordo com a idade (L1 para o/a mais jovem e L10 para o/a mais velho/a). As cinco duplas foram: L1/L7, L2/L6, L3/L8, L4/L10 e L5/L9.

3. O estagiário docente é o autor deste artigo. Como foi bolsista durante o primeiro ano de mestrado e precisou realizar estágio docência em um componente curricular da graduação, conforme exigência da Coordenação de Aperfeiçoamento de Pessoal de Nível Superior (CAPES), ele escolheu o componente curricular estágio supervisionado, mencionado anteriormente, pela proximidade teórica existente entre o conteúdo do componente curricular a ser abordado e as bases conceituais da própria pesquisa de mestrado, constituindo-se em seu campo de geração de dados.
} 
a leitura e a discussão de textos que fundamentariam as práticas dos licenciandos no campo de estágio ${ }^{4}$; b) na segunda etapa, ocorreu o período de observação e regência de aulas no campo de estágio, bem como encontros semanais para discussões sobre planejamento e compartilhamento de experiências, ideias, dúvidas e sugestões; e c) apresentação de textos acadêmicos escolhidos pelos licenciandos e escrita e defesa dos relatos de experiência.

Foi nesse contexto que realizamos uma pesquisa (BARROS, 2019) qualitativa de base etnográfica (ANDRÉ, 2005; MOREIRA ${ }_{i}$ CALEFFE, 2008), em que apresentamos, aos licenciandos de uma turma de estágio supervisionado do $3 .^{\circ}$ ano do Ensino Médio do curso de Letras - língua inglesa, a proposta de utilizar o smartphone em suas respectivas aulas de língua inglesa no campo de estágio. Com isso, acompanhamos a referida turma durante um semestre e, a partir das tentativas de uso do smartphone, refletimos, juntamente com os participantes, acerca dos usos das tecnologias digitais no ensino de língua inglesa à luz da perspectiva teórica dos letramentos digitais.

Para o recorte aqui apresentado, considerando como pano fundo a configuração social pós-moderna, marcada pela incerteza, pela fluidez (BAUMAN, 2001) e pela pressão de se "tecnologizar" a aprendizagem (MATTOS, 2015), objetivamos discutir sobre as influências das representações ou dos mitos acerca do que é ser professor nas (auto)percepções dos licenciandos "nativos digitais" frente às práticas envolvendo o smartphone por eles realizadas. Nesse sentido, dentre os dados gerados na pesquisa, enfocaremos aqueles em que os licenciandos, devido à proposta de uso do smartphone, se viram desafiados a lidar de forma mais explícita, em alguns momentos, com a possibilidade do incerto, do inesperado e do novo. Portanto, analisamos, neste artigo, algumas notas de campo e alguns fragmentos dos relatos de experiência elaborados pelas duplas de graduandos, da questão treze $\mathrm{e}^{5}$ de um questionário inicial (aplicado no início do estágio supervisionado) e das questões ${ }^{6}$ dois, cinco e sete de um questionário final (aplicado no final do componente curricular mencionado) que, na nossa leitura, flagram tais momentos.

Este artigo está organizado em duas seções, além destas Considerações iniciais e das Considerações finais. Na primeira seção, "Identidades e formação docente no século XXI", discutimos acerca da construção de identidades, situando tal discussão na área de formação de professores na contemporaneidade e, na segunda seção, "Passos percorridos pelos estagiários: entre incertezas, dificuldades e superações", abordamos questões relativas à construção identitária desses licenciandos frente a práticas envolvendo o smartphone em suas respectivas aulas no campo de estágio.

\section{IDENTIDADES E FORMAÇÃO DOCENTE NO SÉCULO XXI}

Ao tratar da formação de professores, mais especificamente de professores de línguas, entendemos que é importante considerar que as características da pós-modernidade apontam para a dissolução dos sólidos padrões homogêneos, atingindo diretamente, por exemplo, "as noções de identidade ao questionar a ideia de 'origem', elemento fundamental para a afirmação de quem se é" (MARTINO, 2010, p. 45). O mesmo ocorre ao situarmos as discussões sobre identidades na área de formação de professores, em que a ideia de origem ou de essência que legitimaria o que é ser professor também é contestada.

O conceito de identidade era algo impensável antes do século XVI. Atualmente, é um conceito amplamente discutido e teorizado, sendo formulado e reformulado de acordo com as condições históricas, os períodos ou os movimentos a partir dos quais as preocupações dos teóricos emergem (cf. BENWELL; STOKOE, 2006). De acordo com Woodward (2014) e Benwell e Stokoe (2006), de modo geral, as discussões sobre identidade podem ser entendidas a partir de uma perspectiva essencialista ou de uma perspectiva social construcionista.

A primeira tendência, que aborda as identidades com base em uma origem ou essência, segundo Woodward (2014), parte da premissa de que há uma suposta "verdade" da tradição e da história. Para isso, recorre-se a um passado e/ou a uma tradição como tentativa de recuperar uma verdade, uma unidade, uma essência que dê sentido e legitimidade à identidade que se busca manter no presente, mesmo que esse passado ou essa tradição precise ser

4. O campo de estágio dos licenciandos em Letras-Língua Inglesa foi constituído de cinco turmas de $3 .^{\circ}$ ano do Ensino Médio distribuídas em duas escolas estaduais da cidade de Campina Grande, Paraíba.

5. 13- Considerando que este é o último estágio supervisionado do curso de Letras-Língua Inglesa, você se sente preparado para incorporar as novas tecnologias digitais à sua prática docente? Por quê?

6. 2- Como você avalia o uso que foi feito do smartphone nessa proposta que sua dupla desenvolveu no período de regência do estágio? Houve alguma contribuição? Qual(ais)?; 5- Refletindo sobre sua experiência no campo de estágio, há alguma coisa que você faria de diferente? Por quê?; 7- Quais pontos, momentos ou aspectos desta disciplina de estágio você considera que deveriam ser melhorados ou repensados? Por quê? 
criado. Logo, esse ideal de identidade como algo unificado, centrado, estável, herdado e bem determinado seria efeito das narrativas e das tradições construídas para sua legitimação no presente.

Em relação a segunda tendência, a autora explica que, embora tenhamos a impressão de sermos as mesmas pessoas em diferentes situações, somos "posicionados pelas diferentes expectativas e restrições sociais envolvidas [...], representando-nos, diante dos outros, de forma diferente em cada um desses contextos" (WOODWARD, 2014, p. 31). Ou seja, ao invés de estabelecer uma oposição e buscar negar ou desvalorizar a primeira tendência, a autora a explica como sendo uma interpretação, uma construção social dentre outras possíveis. A tendência social construcionista não substitui a concepção de identidade como um eu "interior" - a essência - por um eu exterior, mas considera a própria noção de um eu interior e suas expressões externas como sendo construídas (cf. BENWELL; STOKOE, 2006), uma vez que identidade seria uma construção, um efeito, um processo de produção e, por isso, seria instável, contraditória e inacabada (SILVA, 2014).

Ao situar tais discussões na área de formação de professores, percebemos a predominância de uma perspectiva essencialista, em que a "verdade", a tradição ou a essência do que é ser professor é revisitada e/ou (re)criada como fonte de legitimação de determinada identidade profissional. Com isso, os formandos ou recém-formados, por exemplo, são posicionados em lugares que, muitas vezes, são por eles criticados durante os cursos de formação. De acordo com Pimenta (1997),

uma identidade profissional se constrói, pois, a partir da significação [sic.] sociais da profissão; da revisão constante dos significados sociais da profissão; da revisão das tradições. Como, também, da reafirmação de práticas consagradas culturalmente e que permanecem significativas. Práticas que resistem a inovações [...] (PIMENTA, 1997, p. 7).

Essas significações sociais acerca da profissão podem ser interpretadas como constituindo uma origem que é/ pode ser retomada para validar determinada identidade que se queira reafirmar no presente. Como exemplo, temos a discussão empreendida por Britzman (2003), sobre mitos culturais - imagens e definições ideais que funcionam de modo a tornar unitária, determinada e certa a realidade que buscam produzir. No caso da formação de professores, esses mitos fornecem uma aparência de ordem, controle, estabilidade e certeza no fazer docente. Com isso, os mitos culturais servem de referência, a partir dos quais, um professor se reconhece como tal ou como não possuidor do que é preciso para se tornar um.

De modo geral, Britzman (2003) apresenta três mitos culturais relacionados à docência. O primeiro reflete a ideia de que tudo depende do professor. Com base nesse mito, o professor precisa controlar os alunos para não ser controlado, pois o controle seria essencial para que houvesse aprendizagem. Assim, caso algo fuja do controle e não ocorra como esperado, a culpa será apenas do professor. O segundo mito propaga a noção de professor como expert, aquele que deve saber todas as repostas. Nessa perspectiva, o professor sente-se em uma constante busca para preencher a falta de conhecimento, uma vez que parece nunca saber o suficiente para ensinar. Por fim, o terceiro mito entende a profissão como um dom, em que alguém nasceria para ser professor. De acordo com esse terceiro mito, a pedagogia é reduzida a técnicas que comporiam um estilo de ensinar. Ao professor, que nasceu para essa profissão, cabe experimentar vários estilos, "como um figurino: você experimenta diferentes personagens até que o personagem correto seja encontrado"7 (BRITZMAN, 2003, p. 231, tradução nossa).

Esses mitos levam a entender a formação docente em termos de o licenciado(ando) estar ou não preparado, focalizando a "eficiência"8 (ALLWRIGHT, 2003) e apagando as contradições e as contingências constitutivas da formação, dos contextos de atuação, bem como dos que neles estão envolvidos, inclusive o próprio profissional (cf. BRITZMAN, 2003). Esse apagamento não é neutro, uma vez que busca produzir e fixar determinada identidade profissional, ao tempo que deslegitima outras. De acordo com Silva (2014), a definição da identidade está sujeita a relações de poder, em que alguns têm o poder de defini-la. Fixar e normalizar uma identidade significa

eleger [...] uma identidade específica como parâmetro em relação ao qual as outras identidades são avaliadas e hierarquizadas. Normalizar significa atribuir a essa identidade todas as características positivas possíveis, em relação às quais as outras identidades só podem ser avaliadas de forma negativa. (SILVA, 2014, p. 83).

7. "[...] like a costume: one tries on different personae until the right".

8. De acordo com Allwright (2003), pesquisas e cursos de formação poderiam não se voltar para a busca de maneiras, técnicas e métodos que podem tornar o ensino "eficiente". Ao invés de as discussões se basearem em um ideal de eficiência, parece ser mais produtivo, para o autor, que a noção de entendimentos esteja no centro. Assim, Allwright (2003) sugere que professores e alunos deixem de ser concebidos como aqueles que, em pesquisas, cursos e/ou aulas, buscam resultados eficientes, para serem entendidos como pessoas ativamente engajadas na negociação e construção de entendimentos a respeito de algo (atividade, aula, conflito, problema, metodologia, formação etc). 
A esses mitos, soma-se a pressão de "tecnologizar" a aprendizagem (MATTOS, 2015), levando o professor a se perceber diante da necessidade de "dominar" as TDIC para que possa inseri-las em suas aulas, conforme é esperado pela naturalização da ideia de que a mera inserção das TDIC pode melhorar a qualidade da educação (BARTON, LEE, 2015; CORACINI, 2007; MORAN, 2000; PISCHETOLA, 2016). Nesse sentido, Coracini (2007, p. 210) argumenta que a naturalização das tecnologias digitais como base para um bom desempenho pedagógico "instaura, no imaginário do professor, uma situação de conflito, despertando, ao mesmo tempo, o desejo de dominálas e a angústia diante da constatação de seu desconhecimento e das dificuldades".

Essa pressão a qual Mattos (2015) se refere e o conflito a respeito do desejo de domínio das TDIC discutido por Coracini (2007) são ainda mais salientados para os professores que se formaram ou estão se formando recentemente, e que nasceram a partir das duas últimas décadas do século XX. Como exemplo desses professores, temos o autor deste artigo e os licenciandos participantes da pesquisa (cf. BARROS, 2019), que nasceram na última década do século XX, caracterizando-se, de acordo com Prensky (2001), como "nativos digitais" ${ }^{\text {. }}$.

Segundo Prensky (2001), no período em que publicou o artigo sobre nativos e imigrantes digitais, havia uma espécie de descompasso em que os professores eram os imigrantes digitais e, portanto, não falavam a "mesma língua" que os alunos, os nativos digitais. $\mathrm{O}$ autor explica que os professores, na época, precisavam dominar as tecnologias para ensinar os nativos digitais, "a menos que queiramos deixar de lado a questão da educação dos Nativos Digitais, até que eles cresçam e eduquem eles mesmos [...]"10 (PRENSKY, 2001, p. 3, tradução nossa).

De acordo com essa concepção que orienta muitas discussões sobre formação docente, os professores recémformados no final desta segunda década do século XXI, a exemplos dos participantes da pesquisa aqui abordada, sentem-se mais pressionados a saberem utilizar as TDIC em sala de aula, uma vez que são nativos digitais ensinando outros nativos digitais. Essa divisão entre nativos digitais e imigrantes digitais, conforme crítica de Barton e Lee (2015), com a qual concordamos, pode ter sido útil para aquele momento histórico em que havia uma geração sem qualquer tipo de contato com internet e/ou TIDC, mas "a ideia de nativos digitais [...] mascara a variedade de conhecimentos e experiências" (BARTON; LEE, 2015 p. 23).

Isso porque sugere que os sujeitos nascidos a partir das duas últimas décadas do século XX têm tido as mesmas experiências e os mesmos acessos às mesmas TDIC para os mesmos usos e propósitos. Logo, espera-se que os professores "nativos digitais" saibam aplicar as TDIC no ensino, expectativa "que se manifesta [...] por meio da referência às habilidades dos "nativos digitais"" (PISCHETOLA, 2016, p. 10, grifo da autora). Entender que apenas habilidade técnica não é letramento digital, segundo Pischetola (2016, p. 44), é essencial para "superar a crença de que exista um 'antes' e um 'depois' das mídias digitais e de que haja uma geração que entende a época atual porque já nasceu com elas".

Além de ser causada por essa "necessidade" de domínio das TDIC, uma vez que são nativos digitais, a angústia também é formada pela perda do poder (aparente) que se tinha sobre o aluno (cf. CORACINI, 2007), poder esse construído, também, pelos mitos culturais discutidos por Britzman (2003). Assim, percebe-se que o professor, o licenciando ou o recém-formado, ao estar inserido em um contexto de ensino, pode se sentir resumido à identidade produzida pelos mitos culturais e pela exigência do domínio das TDIC, os quais podem ser entendidos como constituintes de um referencial descritivo (e impositivo) do que ele deve se tornar, do que ele deve desejar alcançar enquanto profissional e do que esperam que ele se torne. Caso esses aspectos naturalizados e normalizados não sejam assumidos/incorporados, o profissional poderá ser (auto)avaliado de forma negativa, gerando o sentimento de angústia, de culpa e de não possuir o que é preciso para ser um professor.

Por esse motivo, entendemos que pensar a formação de professores, mais especificamente a formação de professores de línguas, na pós-modernidade, implica romper com a formação centrada no treinamento, no controle, na reprodução e na transmissão de conteúdos relativos ao componente curricular que esse profissional em formação ensina(rá). Isso porque parece ser mais condizente com o contexto atual levar em consideração a necessidade de construção de "identidades de profissionais abertos à instabilidade, ao encontro com o novo" (GIMENEZ, 2011, p. 51-52), pois "o contexto de sala de aula configura-se como um espaço no qual identidades fluidas e contraditórias [...] se mesclam, se fundem e se movem" (MEDRADO; DOURADO, 2015, p. 10). Dialogando com o que é defendido por Gimenez (2011), Moran (2000, p. 29), ao tratar da formação de professores e o uso de tecnologias, explica que

9. Segundo Prensky (2001), as pessoas que nasceram a partir das duas últimas décadas do século XX são 'nativos digitais', pois são a primeira geração que nasceu em meio ao desenvolvimento tecnológico.

10. "So unless we want to just forget about educating Digital Natives until they grow up and do it themselves [...]". 
precisamos aprender a equilibrar o planejamento e a criatividade, "a aceitar os imprevistos [...], a gerenciar o que podemos prever e a incorporar o novo, o inesperado".

Com isso, poder-se-ia evitar a angústia daquele que não facilmente se deixa ser posicionado na identidade previamente estabelecida ou que, ao se render às expectativas e restrições sociais que o posiciona, percebe-se como não preparado, frente à instabilidade e ao contraditório que constituem o fazer docente. Acreditamos que a perspectiva de estágio como pesquisa ${ }^{11}$ (PIMENTA; ANASTASIOU, 2002) pode possibilitar o desenvolvimento de identidades mais abertas ao novo, que entendem a falta, o contraditório e a contingência como constitutivos do contexto educacional, buscando perceber e compreender o funcionamento desses aspectos no contexto em que atua, bem como utilizá-los (e não tentar apagá-los ou controlá-los) como recurso pedagógico (COSTA, 2014).

\section{PASSOS PERCORRIDOS PELOS ESTAGIÁRIOS: ENTRE INCERTEZAS, DIFICULDADES E SUPERAÇÕES}

Devido à proposta de uso do smartphone nas aulas de língua inglesa do estágio supervisionado do $3 .^{\circ}$ ano do Ensino Médio, os licenciandos se viram desafiados a lidar de forma mais explícita, em alguns momentos, com a possibilidade do incerto, do inesperado e do novo, independente do planejamento realizado. Para esta análise, abordamos notas de campo e fragmentos dos relatos de experiência, da questão treze do questionário inicial e das questões dois, cinco e sete do questionário final que, na nossa leitura, flagram esses momentos.

No relato de experiência, L3 e L8 explicam que, com a proposta de uso do smartphone, sentiram-se inseguras:

\section{Excerto 1}

A proposta [...] de trabalharmos em nossas aulas com o smartphone na vertente do letramento digital foi um dos desafios mais difíceis pelo qual passamos. Especialmente, pelo fato de serem aulas de inglês, pois acreditávamos que o smartphone acabaria se tornando uma distração para aqueles estudantes que não simpatizam com a língua estrangeira. (RED ${ }^{12}$ L3/L8, 2018, p. 7, grifo nosso).

As estagiárias explicam que, diante das dificuldades existentes no campo de estágio em que iriam atuar, como a falta de internet, o uso do aplicativo WhatsApp foi uma alternativa que encontraram. Mesmo tendo encontrado uma forma de utilizar o smartphone e elaborado o plano de aula, a dupla ainda estava insegura: "Sendo assim, já tínhamos o tema e uma base de como usar essa ferramenta tecnológica nas aulas, a única dúvida era se daria certo" (RED L3/L8, 2018 , p. 8). O receio inicial sobre o que e como fazer fora substituído pela insegurança frente à possibilidade de não domínio e controle sobre os alunos durante a realização da proposta, isto é, o receio de que no WhatsApp os alunos "soltem-se" do controle (ilusório) que se imagina ter sobre eles na sala de aula.

Conforme explicam no relato de experiência, a dupla L3/L8 temia que os alunos desviassem do foco do grupo:

\section{Excerto 2}

[...] uma das nossas propostas foi criar um grupo no aplicativo WhatsApp, já que era a única forma de utilizar a tecnologia fora da escola, tendo em vista que o espaço escolar não possuía acesso à internet. [...] O nosso maior medo era que, com a criação do grupo no Whats App, os alunos desviassem o foco do nosso objetivo, mas o que aconteceu foi uma aceitação enorme por parte deles. (RED L3/L8, 2018, p. 3, grifo nosso).

Como podemos observar, L3 e L8 explicam, no Excerto 1, que a proposta do uso do smartphone foi "um dos desafios mais difíceis". Ao explicarem o porquê de ter sido tão difícil, argumentam que a tecnologia poderia causar distração e, de forma mais explícita, no Excerto 2, afirmam temer que, com a criação do grupo no WhatsApp, "os alunos desviassem o foco", utilizando o vocábulo "medo" para se referir a essa preocupação.

As tecnologias digitais parecem contestar concepções que dão origem à identidade docente, questionando o suposto poder e controle que o professor teria sobre os alunos. Como exemplo, as estagiárias L3 e L8, ao planejarem a proposta de criação do grupo no WhatsApp, sentem-se inseguras, pois percebem que não teriam como controlar

11. "[...] a pesquisa, como investigação de algo, lança-nos na interrogação, pede reflexão, crítica, enfrentamento com o instituído, descoberta, invenção e criação" (PIMENTA; ANASTASIOU, 2002, p. 200). De acordo com Pimenta e Anastasiou (2002), entender a sala de aula como espaço de investigação e, portanto, pesquisar a própria prática demonstra a profissionalidade do docente, que envolve a capacidade de desenvolver alternativas diante de problemas e crises, e não buscar alternativas/soluções prontas e elaboradas por terceiros.

12.A abreviação RED (Relato de Experiência Didática) será utilizada nas referências das citações diretas dos relatos de experiência elaborados pelos licenciandos. 
todas as ações que os alunos do Ensino Médio pudessem vir a fazer com o smartphone, abrindo espaço para práticas outras sem que elas ao menos percebessem. Essa origem, no caso dos Excertos 1 e 2, diz respeito ao mito de que tudo depende do professor, cabendo-lhe manter os alunos sob controle, uma vez que isto seria um pré-requisito para que houvesse aprendizagem, de acordo com um dos mitos culturais (BRITZMAN, 2003). Isso pode gerar angústia ${ }^{13}$ (CORACINI, 2007), uma vez que a dupla L3/L8 parece buscar desenvolver propostas que dialogam com a natureza das práticas realizadas na sociedade digital ao mesmo tempo em que "coloca em risco" um dos pilares (o controle) que serve de referência na construção da identidade docente amplamente naturalizada e normatizada (BRITZMAN, 2003; WOODWARD, 2014).

No entanto, esquecem-se de que este controle, mesmo quando não há o uso de tecnologias digitais em sala de aula, é quase utópico. Porém, a possibilidade (potencializada) dessa perda do controle causa receio naquele que assume essa identidade de professor. Isso porque, embora não seja listado de forma explícita o que se espera de um professor, tem-se construído, ao longo da história, características que são compartilhadas, valorizadas e assumidas, logo cobradas, pela sociedade, pelos alunos, pelos pais e pelos professores já em exercício que o recém-formado possua (BRITZMAN, 2003; PIMENTA, 1997; WOODWARD, 2014).

Contudo, L3 e L8 avaliam de forma positiva a experiência realizada. Para a dupla, a participação dos alunos no WhatsApp foi produtiva, pois notaram

\section{Excerto 3}

um envolvimento maior por parte dos alunos, inclusive, alguns que mal falavam na aula [...], a criação do grupo nos forneceu material para refletirmos e para pensarmos em soluções ou estratégias que, de alguma maneira, possa contribuir na melhoria de nossas práticas. (RED L3/L8, 2018, p.10).

Essa avaliação positiva, de superação das dificuldades encontradas, demonstra um exemplo bem ilustrativo da noção de estágio como pesquisa, principalmente quando a dupla explica que a experiência serviu para reflexão de como desenvolver estratégias que possam melhorar as práticas docentes. Isso reflete uma concepção de sala de aula como espaço de pesquisa, em que os obstáculos encontrados se tornam recursos produtivos para construção de práticas sensíveis às especificidades contextuais (PIMENTA; ANASTASIOU, 2002). Tal postura relaciona-se com o desenvolvimento de uma identidade profissional aberta ao novo e ao incerto, como defende Gimenez (2011).

No entanto, também podemos considerar que outro fator contribuiu para que a dupla tenha avaliado positivamente o uso que fizeram do smartphone. O receio da dupla L3/L8 acerca de a tecnologia se tornar fonte de distração (cf. Excerto 1) ou que os alunos desviassem do seu objetivo (cf. Excerto 2) não aconteceu. Diante do não cumprimento dessa expectativa negativa, talvez, as licenciandas podem ter interpretado que mantiveram o controle sobre os alunos e, portanto, possuem as características básicas para ser professor (cf. BRITZMAN, 2003).

Por fim, ao fazer uma reflexão final no relato de experiência a respeito do uso das TDIC nas escolas e da pressão que os professores, em geral, sentem para "tecnologizar" a aprendizagem, a dupla L3/L18 explica que

\section{Excerto 4}

quando se pede que exista um ensino voltado para os letramentos, é necessário compreender que os profissionais muitas vezes não estão preparados para lidar com os avanços da tecnologia. Portanto, é preciso que exista uma capacitação profissional desses professores, o que também é deixado de lado no contexto brasileiro atual. (RED L3/L8, 2018, p. 11, grifo nosso).

A crítica empreendida no Excerto 4 relaciona-se com a nossa crítica, ao discutirmos, em Barros (2019), que não é a mera presença e inserção das TDIC no contexto escolar que resultará em melhoras educacionais. Percebe-se também que a dupla, mesmo não utilizando os termos/conceitos que trazemos, questiona a ideia de "nativo digital" (PRENSKY, 2001), uma vez que esses licenciandos, com base no período de tempo que Prensky (2001) utiliza para classificar alguém como nativo digital ou imigrante digital, são nativos e fazem esse tipo de crítica, ressaltando que "os profissionais muitas vezes não estão preparados para lidar com os avanços da tecnologia" (cf. Excerto 4). Logo, essa expectativa que temos de que os professores mais jovens, por serem "nativos digitais", possam melhor

\footnotetext{
13. Conforme explicado anteriormente, Coracini (2007) argumenta que com a naturalização das TDIC como base para um bom desempenho pedagógico, instaura-se uma situação de conflito, em que o professor tem, ao mesmo tempo, o desejo de dominar as tecnologias digitais e a angústia diante das dificuldades.
} 
desenvolver práticas que envolvam tecnologias parece não se sustentar (PISCHETOLA, 2016), embora constitua uma característica que se espera ser assumida por aqueles posicionados na identidade de professor.

Outro exemplo que demonstra essa fragilidade da noção de "nativos digitais" pode ser observado no Excerto 2, apresentado anteriormente. O fato de L3 e L8 entenderem o WhatsApp como a única alternativa de utilização do smartphone demonstra uma limitação sobre como utilizá-lo. No entanto, isso salienta que, embora os licenciandos (e o estagiário docente) pudessem ser classificados como "nativos digitais", encontram dificuldades e limitações acerca de possibilidades de como utilizar o smartphone na sala de aula, resumindo tal tecnologia ao aplicativo WhatsApp. Essa dificuldade dialoga com a crítica que Pischetola (2016, p. 44) faz à noção de nativo digital: é preciso superar a ideia de que "exista um 'antes' e um 'depois' das mídias digitais e de que haja uma geração que entende a época atual porque já nasceu com elas".

Um comentário que se alinha à discussão a respeito do Excerto 2 e do Excerto 4 foi feito por L1 na questão treze do questionário inicial, antes mesmo do início dos trabalhos no campo de estágio. Ao ser questionada sobre se sentir preparada para incorporar as novas tecnologias digitais em sua prática docente, tendo em vista que estava cursando o último estágio supervisionado do curso, L1 explica que se sente "um pouco, mesmo estando inserida no contexto (era digital) ainda me vejo um pouco insegura em como fazer uso da tecnologia [...]". A licencianda afirma estar pouco preparada, mesmo podendo ser classificada como nativa digital (PISCHETOLA, 2016; PRENSKY, 2001). O uso da conjunção "mesmo" parece demonstrar, para além da relação entre orações, mais que uma ideia contrária, uma autopercepção que se mostra contrária ao que seria esperado da licencianda, ao assumir a posição de professora no século XXI. Ao complementar expressando que "ainda me vejo um pouco insegura", nos parece que ela assumiu como "natural" essa expectativa, que ainda não alcançou, mas parece almejá-la.

Essas expectativas naturalizadas e que parecem constituir a identidade docente também podem causar angústia no profissional (em formação), tanto em forma de medo de não estar preparado ou de que algo possa impossibilitar que se assuma a identidade normatizada/fixada, como em forma de frustação por não ter atendido tudo que seria preciso para ser professor (BRITZMAN, 2003; CORACINI, 2007). Isso se relaciona com o que Silva (2014) argumenta acerca da normalização e fixação de determinada identidade, tornando-se o parâmetro a partir do qual identidades que difiram são avaliadas de forma negativa.

Vejamos alguns exemplos de autoavaliação negativa que alguns licenciandos fizeram acerca da tentativa de uso do smartphone em suas respectivas práticas no campo de estágio na questão dois do questionário final. A dupla L5/L9, embora fazendo avaliação positiva da experiência no campo de estágio, relata: "gostamos muito do desenvolvimento das atividades, da turma participativa e das discussões" (RED, L5/L9, 2018, p. 10), o mesmo não ocorre ao tratar especificamente sobre o uso do smartphone.

$\mathrm{Na}$ questão dois do questionário final, que pede para o licenciando avaliar o uso do smartphone que fora feito no período de regência das aulas, L9 explica que "Não ficamos ${ }^{14}$ satisfeitos com a abordagem que utilizamos. Foi perceptível que não alcançamos nossos objetivos devido à forma que manuseamos o sistema tecnológico [...]". A questão cinco do mesmo questionário pergunta se há algo que o licenciando faria diferente e L9, ao responder, afirma que mudaria "a maneira que optamos em inserir o uso do celular em sala de aula. Apesar de ser uma ferramenta próxima no dia a dia, não é tão simples aplicar a mesma dentro do contexto de ensino". Essa afirmação de L9 contesta a noção de nativo digital (PRENSKY, 2001), uma vez que o licenciando seria considerado nativo digital, estava em um contexto de Ensino Médio em que os alunos também são nativos digitais, e teve dificuldade em utilizar o smartphone nas suas aulas. Essa dificuldade ecoa a crítica de Pischetola (2016), ao argumentar que não é o fato de uma geração ter nascido durante o desenvolvimento das TDIC que ela as entenderá ou possuirá uma espécie de conjunto de habilidades - as habilidades dos nativos digitais - passível de aplicação em qualquer contexto, inclusive o da sala de aula.

Ressaltando esta crítica, temos, na afirmação de L9, o uso do verbo aplicar, pois, segundo L9, "não é simples aplicar a mesma dentro do contexto de ensino". Tal utilização sugere uma noção utilitarista, em que, ao dominar as habilidades necessárias para a utilização do smartphone no cotidiano, bastaria aplicá-las na sala de aula. Essa concepção pode ter sustentado a ideia de nativo digital discutida por Prensky (2001), tendo em vista que o autor argumenta em seu artigo que, caso os professores (imigrantes digitais) não quisessem tratar da educação dos nativos digitais,

14. Ele conjuga o verbo na primeira pessoa do plural porque, conforme já explicamos, o estágio foi realizado em dupla. 
deveriam esperar que estes cresçam e tratem disso eles mesmos, como se fosse simplesmente pôr em prática, aplicar algo que é feito fora da escola (PIMENTA; LIMA, 2017; PRENSKY, 2001).

De modo semelhante à autoavaliação negativa feita por L9, a licencianda L5 avalia como "ruim" o uso feito do smartphone pela sua dupla (L5/L9). Ademais, o modo como todo o questionário final foi respondido por ela (cf. Fig. 1) pode ser interpretado como representativo de uma frustação, culpa ou descontentamento de não ter alcançado alguma espécie de parâmetro ou ideal previamente estabelecido.

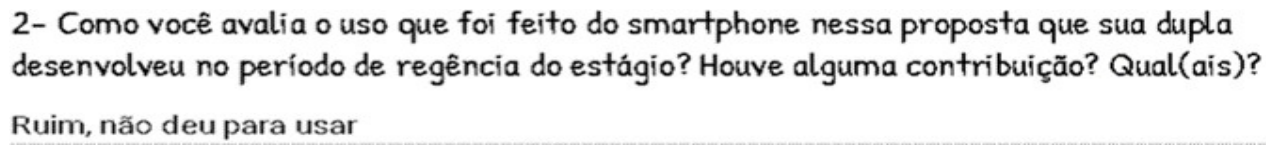

Figura 1. Amostra do questionário final respondido por L5.

Fonte: Questionário final.

A exemplo da amostra apresentada (cf. Fig. 1), L5 respondeu todo o questionário com respostas curtas, sem argumentação. Isso pode ser representativo do sentimento de frustação gerado com a experiência. Em uma última orientação para o relatório final, após o término do período de regência das aulas, a dupla L5/L9 explicou que ficou com a "sensação de que não conseguiu abordar o letramento digital efetivamente" (Notas de campo - 13 de julho de 2018). Ao expressarem que não conseguiram abordar a perspectiva teórica efetivamente, entendemos que isso revela o desejo de completude, de domínio, de aplicação de algo conforme modelo planejado/idealizado. Como a experiência não ocorreu exatamente como planejado, há a sensação de não se ter conseguido, remetendo-nos à sensação de culpa discutida por Britzman (2003), ao tratar do mito de que tudo depende do professor. Fundamentado neste mito, caso algo não ocorra como deveria, a culpa seria do professor que não entendeu ou não aplicou a proposta corretamente.

Logo, isso pode gerar angústia e sentimento de não ter conseguido o que era preciso, uma vez que o foco está na aplicabilidade eficiente, que é criticado por Allwright (2003), embora a perspectiva teórica e todas as discussões que orientaram o estágio criticassem essa visão positivista de aplicabilidade. Vale observar que para L5 essa sensação de frustação parece ter sido mais forte, pois, ao avaliar o uso feito do smartphone, ela responde que foi "ruim, não deu pra usar" (cf. Fig. 1), mesmo tendo usado.

O estagiário L9, por sua vez, na última orientação para o relatório final, ao refletir sobre a experiência do estágio em que buscou incorporar o smartphone em suas aulas, juntamente com L5, explica que "a tecnologia dá pra trabalhar, mas tem que ser bem planejado, pois não é fácil, não adianta ter o domínio" (Notas de campo - 13 de julho de 2018). A afirmação sugere que o licenciando começa a questionar as noções de controle, de domínio e de aplicabilidade que cercam as representações sobre ser professor que, provavelmente, orientaram a experiência do período de regência das aulas (BRITZMAN, 2003).

Esse desejo (imposto) de assumir a identidade docente conforme expectativas e restrições sociais que foram sendo construídas, normalizadas e naturalizadas e, portanto, evitar o incerto, o medo, o receio, o novo, a instabilidade, aponta para a necessidade/desejo de um passo a passo, de um modelo "correto" a seguir. Essa possível necessidade, no contexto investigado, pode ser percebida na fala de uma licencianda no dia em que apresentamos a proposta de 
usar o smartphone nas aulas do estágio: "você nos propôs isso, agora tem que dizer como é que a gente vai fazer" (Notas de campo - 24 de maio de 2018).

Ainda, a insegurança e o medo relatados pelos licenciandos podem ser interpretados como indicadores de um desejo de controle, ressaltando o quão forte são os mitos e representações acerca do professor (BRITZMAN, 2003; PIMENTA, 1997). No entanto, isso pode gerar angústia diante do desejo de controle e constatação de sua impossibilidade (cf. CORACINI, 2007). Salientamos, também, que essa angústia e receio da perda de controle podem ter sido causados pelo contexto de estágio, em que os licenciandos estavam cursando o estágio supervisionado, sendo avaliados e acompanhados pelo professor-formador e pelo estagiário docente. Com isso, além dos mitos culturais e da pressão para "tecnologizar" a aprendizagem, a presença do professor-formador e do pesquisador, que também estava como estagiário-docente, bem como a proposta de uso do smartphone se constituem ou podem ter sido interpretados pelos licenciandos como as expectativas e as restrições (WOODWARD, 2014) que moldam a identidade docente, com a qual os estagiários podem ter se sentido pressionados a assumir para que fossem aprovados no componente curricular de estágio.

Em outros fragmentos dos relatos de experiência e dos questionários, em que avaliam a experiência do estágio supervisionado, alguns licenciandos demonstram, de acordo com a nossa interpretação, maior receptividade ao incerto. Conforme relato de experiência da dupla L4/L10, a instabilidade acerca dos acontecimentos e da execução do planejamento realizado durante o período de regência das aulas era algo esperado:

\section{Excerto 5}

Os obstáculos não foram surpresa, já que esta não foi nossa primeira experiência como estagiários da rede pública de ensino do nosso país. Entretanto, o sentimento de termos conseguido plantar a semente da reflexão cidadã a respeito da temática escolhida foi dos melhores e mais satisfatórios; sentimento este reforçado ao recebermos, no final da regência, gratificantes mensagens dos nossos ex-alunos, elogiando nosso trabalho e demonstrando que cumprimos com nosso dever. (RED L4/L10, 2018, p. 12, grifo nosso).

Embora tenham ocorrido imprevistos, a dupla afirma não ter havido surpresa, levando-nos a entender que há uma compreensão de que esses imprevistos são parte do contexto de atuação e não resultado de um despreparo ou de algo que foi mal planejado/executado pelo estagiário. Isso ecoa o argumento de Moran (2000), ao defender a necessidade de equilíbrio entre planejamento e criatividade, aceitação dos imprevistos e incorporação do inesperado. Ao tratar os imprevistos sob o substantivo "obstáculo", podemos inferir que foram entendidos como barreiras a serem consideradas, sugerindo o desenvolvimento de práticas sensíveis a tais "obstáculos" e, portanto, contextualmente orientadas, aproximando-se da noção de estágio como pesquisa (PIMENTA; ANASTASIOU, 2002).

Esse tipo de percepção, a nosso ver, contribuiu para que, mesmo havendo "obstáculos", eles avaliassem de forma satisfatória a experiência realizada, ao invés de se culparem pela ocorrência dos imprevistos. Com isso, distanciam-se dos mitos de que tudo depende do professor, no sentido de manter o controle, bem como da noção de que os desvios que possam ocorrer sejam resultado de uma má aplicação e, assim, responsabilidade do professor (BRITZMAN, 2003). Eles parecem se ver desvinculados da busca por resultados eficientes, numa lógica positivista, para construção de entendimentos, como defende Allwright (2003).

De forma semelhante, a reflexão da dupla L3/L8 sugere uma compreensão de que os acontecimentos que fogem do que fora planejado no cotidiano escolar não são exceções ou resultado de um despreparo do professor, mas parte constitutiva da atividade docente. Nas palavras da dupla,

\section{Excerto 6}

Acreditamos que mesmo com as dificuldades enfrentadas por nós, conseguimos entender e fazer uso do letramento digital. E isso foi importantíssimo para nossa formação, aprendemos a entender os desafios do cotidiano, superar as dificuldades e a buscar soluções [...], para que desse modo, ele [o aluno] seja capaz de construir pensamentos críticos [...]. (RED L3/L8, 2018, p. 12, grifo nosso).

No Excerto 6, o foco das dificuldades foi em relação à perspectiva teórica dos letramentos digitais, uma vez que, com base nessa perspectiva, os licenciandos buscaram fazer usos dos smartphones nas aulas que ministraram no período de regência do estágio. Essa experiência parece ter proporcionado uma relação mais direta e consciente com "os desafios do cotidiano" (cf. Excerto 6), com as incertezas que fazem parte da profissão, posto que precisaram 
lidar com elas, desenvolvendo soluções/alternativas, ao invés de se culpar, buscando identificar o que foi aplicado/ executado de forma não correta (BRITZMAN, 2003).

A dupla L3/L8 também ressalta a importância do estágio supervisionado em promover o compartilhamento de ideias, de dúvidas e de incertezas para construção de saídas ou soluções para os desafios. No trecho abaixo, a dupla explica como esse espaço de compartilhamento foi importante frente ao desafio de uso do smartphone:

\section{Excerto 7}

Sendo assim, buscamos encontrar saídas, junto com nossos colegas de turma, para esse desafio de utilizar o smartphone. Um dos pontos que sempre achamos cruciais nas aulas de estágio é a troca de experiências que acontece entre nós [...], foi através da troca de experiência com os colegas de estágios que tivemos uma ideia de como utilizá-lo em sala [...]. (RED L3/L8, 2018, p. 7-8, grifo nosso).

O Excerto 7, assim como o Excerto 6, demonstra a importância do estágio supervisionado na formação docente. Ao invés de ser concebido como espaço neutro, de mera aplicação de métodos, técnicas e abordagens, os licenciandos buscam desenvolver práticas a partir das especificidades contextuais do campo de estágio, preparandose para lidar melhor com os imprevistos, isto é, deixando de lado a busca de técnicas e modelos eficientes para focar na construção de entendimentos situados, contextualmente sensíveis, para o desenvolvimento de práticas docentes (ALWRIGHT, 2003).

Ao responder sobre as contribuições do estágio supervisionado no $3 .^{\circ}$ ano do Ensino Médio, na questão sete do questionário final, L4 afirma que se sente "uma professora capaz de olhar pro outro [..] Então quero ir em busca de ser uma profissional cada vez mais capaz de abraçar o outro e trazer suas necessidades para sala de aula" e que, assim, estará concebendo a sala de aula "como espaço também de desabafo e troca de experiências, não apenas transmissão de conteúdos".

Como foi possível notar ao longo da análise, independente da perspectiva teórica que oriente o componente curricular estágio, o curso ou o fazer docente, haverá conflitos, contradições, uma vez que as identidades, os contextos e as situações não são homogêneos, imutáveis, controláveis ou previsíveis. A proposta de uso do smartphone possibilitou que alguns licenciados questionassem e refletissem sobre os mitos e as representações que fundamentam o que é ser professor.

\section{CONSIDERAÇÕES FINAIS}

Neste artigo, buscamos discutir as influências das representações ou dos mitos acerca do que é ser professor nas (auto)percepções dos licenciandos "nativos digitais" frente às práticas envolvendo o smartphone por eles realizadas. A partir da análise, de modo geral, percebe-se uma insegurança inicial sobre a atividade planejada que, após realização no período de regência das aulas, é avaliada positivamente quando se aproxima ou negativamente quando se distancia do que fora planejado.

A insegurança inicial chama a atenção para o fato de que a proposta de uso do smartphone coloca em xeque, de modo mais explícito, alguns mitos que criam, sustentam e naturalizam determinada identidade profissional (BRITZMAN, 2003; WOODWARD, 2014). Os mitos culturais de que tudo depende do professor e de que ele deve ter o controle sobre os alunos (cf. BRITZMAN, 2003), bem como a noção de fazer docente em termos de aplicabilidade se mostraram como bem arraigados no imaginário de alguns estagiários. Esses licenciandos, a exemplo de L5 e L9, demonstraram uma autoculpabilização, ou uma sensação de frustração, de não ter conseguido pôr em prática "de forma correta" os letramentos digitais por meio do uso do smartphone. Isso, somando-se às características do contexto de atuação, algumas dificuldades recursais (sem acesso à internet e ao laboratório de informática) e a dificuldade/limitação sobre como utilizar o smartphone, levou alguns licenciandos a significarem suas referidas práticas de modo negativo, e, em alguns casos, a assumirem uma culpa pelas contingências que constituíram o período de regência das aulas do estágio.

Por outro lado, alguns licenciandos, como L3, L4, L8 e L10, parecem considerar que os desafios, os obstáculos, os imprevistos não são resultados de um despreparo, de uma aplicação incorreta, mas constitutiva do próprio fazer docente. Percebe-se uma compreensão que se inclina para o entendimento de que essas contingências são constitutivas do fazer docente e não resultados de uma aplicação ou um planejamento "incorreto" ou uma 
interpretação equivocada de uma teoria que, portanto, foi erroneamente aplicada. Logo, ao invés da culpa por não ser o suposto professor "nativo digital" (PRENSKY, 2001), reconhece-se as dificuldades e limitações, bem como se busca ampliar as perspectivas, utilizando essas dificuldades e limitações como recursos produtivos para reflexões que poderão fundamentar práticas futuras.

\section{REFERÊNCIAS}

ALLWRIGHT, Dick (2003). Exploratory Practice: rethinking practitioner research in language teaching. Language Teaching Research, v. 7, n. 2, p. 113-141. https://doi.org/10.1191/13621688031r118oa

ANDRÉ, Marli Eliza Dalmazo Afonso (2005). Etnografia da prática escolar. São Paulo: Papirus.

BARROS, Walter Vieira (2019). Letramentos digitais: um estudo com a mediação do smartphone no estágio supervisionado de língua inglesa no Ensino Médio. Dissertação de Mestrado em Linguagem e Ensino. Universidade Federal de Campina Grande, Campina Grande. Disponível em: http://dspace.sti.ufcg.edu.br:8080/jspui/handle/riufcg/6854 Acesso em: 10 maio 2020.

BARTON, David; LEE, Carmen (2015). Linguagem no mundo digital. In: (Org.). Linguagem online: textos e práticas digitais. Tradução: Milton Camargo Mota. São Paulo: Parábola Editorial, p. 11-28.

BAUMAN, Zygmunt (2001). Modernidade líquida. Tradução Plínio Dentzien. Rio de Janeiro: Zahar.

BENWELL, Bethan; STOKOE, Elizabeth (2006). Discourse and identity. Edinburgh, UK: Edinburgh University Press.

BRITZMAN, Deborah P (2003). Practice makes practice: the given and the possible in teacher education. In: Practice makes practice: a critical study of learning to teach. Albany: State University of New York Press, p. 221-241.

CORACINI, Maria José (2007). Pós-modernidade e novas tecnologias - no discurso do professor de línguas. In: . A celebração do outro: arquivo, memória e identidade: línguas (materna e estrangeira), plurilinguíssimo e tradução. Campinas, SP: Mercado das Letras, p. 200-224.

COSTA, Marco Antônio Margarido (2014). Reflexos das políticas itinerantes nas diretrizes curriculares nacionais dos cursos de letras. RBLA, Belo Horizonte, v. 14, n. 1, p. 41-60. https://doi.org/10.1590/S1984-63982013005000028

GIMENEZ, Telma (2011). Narrativa 14: Permanências e rupturas no ensino de inglês em contexto brasileiro. In: LIMA, Diógenes Cândido. (Org.). Ensinar inglês em escolas públicas não funciona? Uma questão, múltiplos olhares. São Paulo: Parábola Editorial, p. 47-54.

MARTINO, Luís Mauro Sá (2010). Comunicação e identidade. São Paulo: Paulus.

MATTOS, Andrea Machado de Almeida (2015). Reflexões sobre o uso de novas tecnologias e a formação de professores de inglês. Scitis, UNIP-SP, v. 3, p. 11-25.

MEDRADO, Betânia Passos; DOURADO, Maura Regina (2015). Uma proposta de transposição didática: a língua inglesa no ensino fundamental II. João Pessoa: Editora da UFPB.

MOITA LOPES, Luiz Paulo (2006). Uma linguística aplicada mestiça e ideológica: interrogando o campo linguista aplicado. In: (Org.). Por uma linguística aplicada indisciplinar. São Paulo: Parábola Editorial, p. 13-44.

MORAN, José Manuel (2000). Ensino e aprendizagem inovadores com tecnologias audiovisuais e telemáticas. In: MORAN, José Manuel; MASETTO, Marcos T.; BEHRENS, Marilda Aparecida. (Org.). Novas tecnologias e mediação pedagógica. Campinas, SP: Papirus, p. 11-66.

MOREIRA, Herivelto; CALEFFE, Luiz Gonzaga (2008). Metodologia de pesquisa para o professor pesquisador. 2. ed. Rio de Janeiro: Lamparina. 
PIMENTA, Selma Garrido (1997). Formação de professores: saberes da docência e identidade do professor. Nuances. v. 3, p. 5-14. https://doi.org/10.14572/nuances.v3i3.50

PIMENTA, Selma Garrido; ANASTASIOU, Léa das Graças Camargos (2002). O docente do ensino superior. In: PIMENTA, Selma Garrido; ANASTASIOU, Léa das Graças Camargos. (Org.). Docência no ensino superior. São Paulo: Cortez, p. 177-200.

PISCHETOLA, Magda (2016). Inclusão digital e educação: a nova cultura da sala de aula. Petrópolis: Editora Vozes; Rio de Janeiro: Editora PUC-Rio.

PRENSKY, Marc (2001). Digital natives, digital immigrants. On the Horizon, v. 9, n. 5, p, 1-6. https://doi. org/10.1108/10748120110424816

SILVA, Tomaz Tadeu (2014). A produção social da identidade e da diferença. In: (Org.). Identidade e diferença: a perspectiva dos Estudos Culturais. 15. ed. Petrópolis, RJ: Vozes, p. 73-102.

WOODWARD, Kathryn (2014). Identidade e diferença: uma introdução teórica e conceitual. In: SILVA, Tomaz Tadeu (Org.). Identidade e diferença: a perspectiva dos Estudos Culturais. 15. ed. Petrópolis, RJ: Vozes, p. 7-72.

Recebido: 15/5/2020

Aceito: 19/1/2021

Publicado: 4/3/2021 